\title{
CONTROL OF AN ELECTRIC VEHICLE HYBRID ENERGY STORAGE SYSTEM
}

\author{
János FERENCZ,1 András KELEMEN, ${ }^{2}$ Mária IMECS 3 \\ ${ }^{1}$ Technical University of Cluj-Napoca, Doctoral School, Faculty of Electrical Engineering, Cluj-Napoca, \\ Romania, janos_ferencz@yahoo.com \\ 2 Sapientia Hungarian University of Transylvania, Faculty of Technical and Human Sciences, \\ Department of Electrical Engineering, Târgu Mureș, Romania, kandras@ms.sapientia.ro \\ 3 Technical University of Cluj-Napoca, Faculty of Electrical Engineering, Doctoral School, \\ Department of Electrical Machines and Drives, Cluj-Napoca, Romania, Maria.Imecs@emd.utcluj.ro
}

\begin{abstract}
In electric vehicles battery life can be prolonged by using hybrid energy storage systems (HESS), which combine high energy density batteries with supercapacitors, characterized by high power density. This paper deals with the control of electronic power converters from an active parallel HESS. The load of the HESS is the electrical motor drive of an electric vehicle. The interfaces between the DC-link and the power sources are four-phase bidirectional DC-DC converters driven in current control mode, based on the current references supplied by an active parallel HESS power distribution algorithm. We present a rule-based fuzzy energy management algorithm for a HESS powered electric vehicle and its simulation in MATLAB/Simulink ${ }^{\circledR}$ environment using the Quasi-Static Simulation (QSS) and Fuzzy Logic toolboxes. Also, simulation results in driving and regenerative braking operation modes of the electric vehicle are presented.
\end{abstract}

Keywords: hybrid energy storage systems, energy management algorithm, bidirectional 4-phase DC-DC converter, power distribution control structure.

\section{Introduction}

The proliferation of electrical vehicles has made an important contribution to the development of hybrid energy storage systems (HESS).

The lifetime of the battery can be extended using another energy storage element such as a supercapacitor, with the role of protecting the battery from high-power stresses.

The power demand is split between the battery and the supercapacitor, but in the case of high driving or braking power needs, the share of the supercapacitor is increased by the HESS energy management algorithm [1].

In the case of acceleration, when the electrical machine power is suddenly increased, supplementary energy is delivered by the supercapacitor and the battery is prevented from having to deliver high power peaks.
In a similar way, in case of regenerative braking, which means high instantaneous power delivered by the electrical machine, the energy storage task is directed by the HESS controller towards the supercapacitor [2].

The fuzzy rule-based HESS energy management algorithm (EMA) applied in this study has three inputs (SOC, SOE and $P_{\text {el_req }}$ ) and two outputs ( $P_{\text {req_sC }}$ and $P_{\text {req_BAT }}$ ), as shown in Figure 1.

The power demand from the different energy sources is determined by the controller, based on the total instantaneous electrical power required by or supplied by the vehicle. The inference algorithm takes into consideration the State of Charge (SOC) of the battery and the State of Energy (SOE) of the supercapacitor as well. 


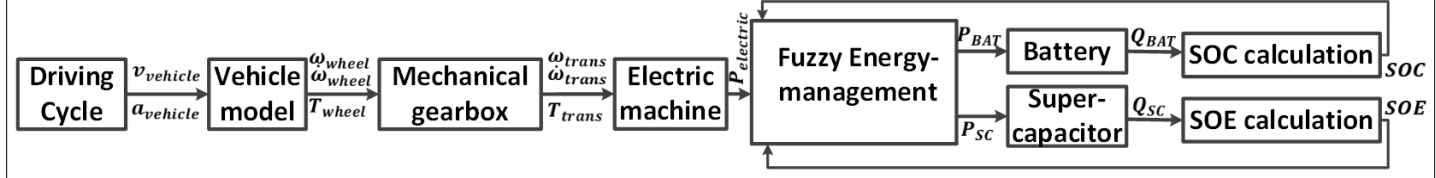

Figure 1. The simulation block diagram of the fuzzy rule-based HESS energy management algorithm.

\section{The fuzzy rule-based HESS energy management algorithm}

The SOC and SOE variables are restricted to the $0 \%-100 \%$ range.

The $P_{\text {el_req }}$ input variable of the HESS EMA corresponds to the electric power required at any given moment to drive or to brake the vehicle.

According to the rule applied in this paper, this instantaneous power is positive when driving the vehicle and it's negative in regenerative braking mode.

The relative power demand from the supercapacitor $\left(P_{\text {req_sc }}\right)$ calculated by the fuzzy inference system, increases when accelerating or braking.

The fuzzy rule-based HESS energy management algorithm has been implemented in MATLAB ${ }^{\circledR}$ using the Fuzzy Logic Designer application.

Three triangular membership functions have been defined corresponding to the state of charge (SOC) of the battery $[3,4,5]$ and three triangular membership functions corresponding to the state of energy (SOE) of the supercapacitor.

In the case of the required electric power $\left(P_{\text {el_req }}\right)$ there have been defined a number of six triangular membership functions have been defined, as it can take also negative values in regenerative braking mode.

The output of the fuzzy inference system is the power that must be delivered by the supercapacitor $\left(P_{\text {req_sc }}\right)$, The range of this variable (positive when driving and negative when braking) is covered by six triangular membership functions.

Additionally, 54 inference rules of the Mamdani-type fuzzy energy management algorithm have been defined, determining the required supercapacitor power in such a manner as to avoid excessive power stress and damage to the battery. The supercapacitor power $\left(P_{\text {req_sc }}\right)$ determined using the 54 inference rules, is shown in Figure 2 , where the above-described input and output membership functions have been considered. The diagram has been generated using the MATLAB $^{\circledR}$, Fuzzy Logic Designer” application. The inputs are the normalized values of the required electric power $\left(P_{\text {el_req }}{ }^{*}\right)$ and of the state of energy (SOE) of the supercapacitor, while the output is the normalized value of supercapacitor power to be delivered $\left(P_{\text {req_SC }}{ }^{*}\right)$.

The diagram illustrates the result of the fuzzy inference in two extreme cases. Let us consider first a sudden increase of the positive $P_{\text {el_req }}$ pow-

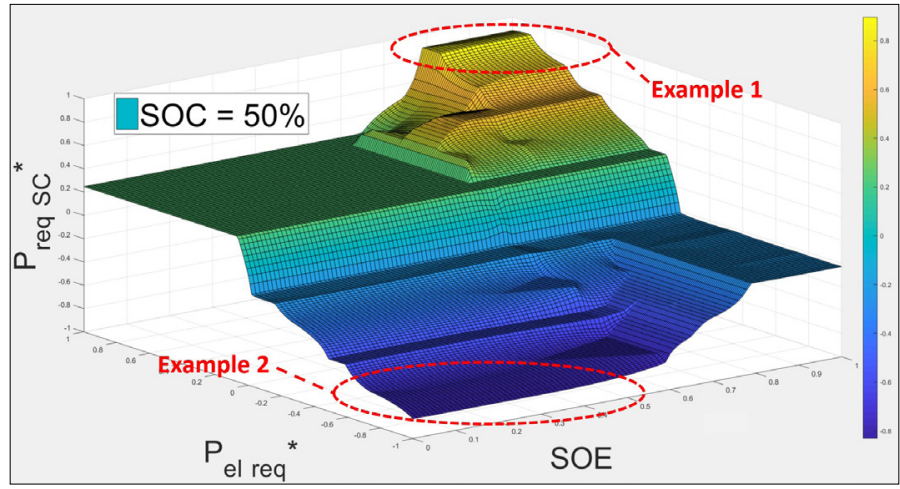

Figure 2. The surface chart of the HESS energy management algorithm for SOC $=50 \%$. Independent varia-bles are the per unit value of the required instantaneous power $\left(P_{\text {el_req }}{ }^{*}\right)$ and the supercapacitor state of energy (SOE), while dependent variable is the per unit value of the power to be delivered by the superca$\operatorname{pacitor}\left(P_{\text {req_sc }}{ }^{*}\right)$. 
er, required to drive the vehicle, while the supercapacitor is almost fully charged. In this case, to avoid the excessive stress of the battery, the supercapacitor delivers the required positive energy at a high instantaneous power level. This case is labelled „Example 1” and is shown in the upper half of the diagram.

Another specific case is the sudden increase of the negative $P_{\text {el_req }}$ power in regenerative braking mode, requiring energy storage in the HESS.

In this situation, if the supercapacitor is almost fully discharged, it can store most of the generated electric energy, and the battery stress is limited to only a fraction of the total power.

This case is labelled as "Example 2" on the surface chart, Figure 2 which shows the result of the fuzzy inference for a $50 \%$ SOC of the battery. The common normalization base of the per unit total instantaneous power $\left(P_{\text {el req }}{ }^{*}\right)$ and the per unit value of the required supercapacitor power $\left(P_{\text {req_SC }}{ }^{*}\right)$ is $P_{N}=16 \mathrm{~kW}$.

\section{Simulation of the energy manage- ment algorithm applied for the elec- trical drive}

The simulation of the energy management algorithm was performed in MATLAB/Simulink ${ }^{\circledR}$ environment, with the electrical drive of the vehicle as the load of the HESS. The first block (see Figure 1) of the drive system model generates the instantaneous values of speed and acceleration for a 20-minute urban drive cycle.

The simulated drive cycle is of type „NEDC” (New European Driving Cycle) and is implemented in the „QSS” (Quasi Static Simulation) Simulink ${ }^{\circledR}$ library. This was the choice in our study because it contains the large number of acceleration and braking cycles needed to test the proposed power sharing algorithm [6].

The next block of the simulation model is the mathematical model of the vehicle, which transforms the linear speed and acceleration resulting from the driving cycle to rotational quantities [6, 7].

The outputs of the vehicle model are the angular speed and acceleration of the wheel, and the torque acting on the wheel. The angular velocity $\left(\omega_{\text {wheel }}\right)$, and angular acceleration $\left(d \omega_{\text {wheel }} / d t\right)$ of the wheel are calculated from the linear speed $\left(v_{\text {vehicle }}\right)$, and linear acceleration of the vehicle $\left(a_{v e-}\right.$ hicle) using the relations:

$$
\omega_{\text {wheel }}=\frac{v_{\text {vehicle }}}{r_{\text {wheel }}} \text {; }
$$

$$
\frac{d \omega_{\text {wheel }}}{d t}=\frac{a_{\text {vehicle }}}{r_{\text {wheel }}}
$$

where $r_{\text {wheel }}$ is the wheel radius.

To determine the torque acting on the wheel, the external forces acting on the vehicle have to be considered. The direction of friction $\left(F_{\text {friction }}\right)$ and air resistance forces $\left(F_{\text {air }}\right)$ is opposite to the direction of motion, and these forces are given by:

$$
\begin{aligned}
& F_{\text {friction }}=\mu m g \cos \alpha ; \\
& F_{\text {air }}=\frac{1}{2} \rho C_{d} A_{\text {front }} v_{\text {vehicle }}{ }^{2} ; \\
& F_{\text {gravity }}=m g \sin \alpha,
\end{aligned}
$$

where $\mu$ is the coefficient of rolling friction, $m$ is the mass of the vehicle, $g$ is the gravitational acceleration, $\rho$ is the air density, $C_{d}$ is the drag coefficient, $A_{\text {front }}$ is the vehicle front area, perpendicular to the direction of motion, while $\alpha$ is the slope. The sum of these forces

$$
F_{\text {load }}=F_{\text {friction }}+F_{\text {air }}+F_{\text {gravity }}
$$

loads the vehicle in steady state. Thus, the forces given in (3) produce the load torque on the axis of the electrical machine.

If, instead of driving on a flat terrain, the vehicle drives uphill or downhill $\alpha \neq 0$ an active force component is also present $F_{\text {gravity }}$ according to $(2, c)$, decelerating or accelerating the vehicle, depending on whether it drives uphill $(\alpha>0)$, or downhill $(\alpha<0)$, respectively.

Considering the inertial force resulting from the vehicle acceleration

$$
F_{\text {inertial }}=m a_{\text {vehicle }}
$$

the dynamic model for variable angular speed of the rotor $\left(\omega_{e m} \neq c t\right.$.), results from:

$$
F_{\text {traction }}=F_{\text {inertial }}+F_{\text {load }}
$$

where $F_{\text {traction }}$ is the traction force acting on the wheel.

According to Figure 1 the block labelled "Driving cycle" generates the instantaneous values of speed and acceleration, from which the "Vehicle model" block calculates the torque acting on the wheel $T_{\text {wheee }}$, which has to be exerted by the gear box in order to accelerate or decelerate the vehicle.

The torque acting on the wheel of the vehicle can be calculated as: 


$$
T_{\text {wheel }}=F_{\text {traction }} r_{\text {wheel }}
$$

The parameters used for simulation were $m=750 \mathrm{~kg}$ - the mass of the vehicle, $A_{\text {front }}=1.8 \mathrm{~m}^{2}$ - the front area of the vehicle, $C_{d}=0,22$ - the drag coefficient, and $\mu=0.008$ - the friction factor.

The next block of the simulation structure in Figure 1 is the gearbox which reduces the angular speed $\left(\omega_{\text {wheel }}\right)$ and acceleration of the wheel, and the torque acting on the wheel ( $\left.T_{\text {wheel }}\right)$, to the axis of the electrical motor, using the gear ratio ( $\left.a_{\text {trans }}\right)$.

The angular velocity $\left(\omega_{\text {trans }}=\omega_{e m}\right)$ and angular acceleration $\left(d \omega_{\text {trans }} / d t\right)$ of the electrical motor axis result from:

$$
\begin{aligned}
& \omega_{\text {trans }}=a_{\text {trans }} \omega_{\text {wheel }} ; \\
& \frac{d \omega_{\text {trans }}}{d t}=a_{\text {trans }} \frac{d \omega_{\text {wheel }}}{d t}
\end{aligned}
$$

The load torque $T_{\text {trans }}$ on the motor axis results from the torque acting on the wheel $T_{\text {wheel }}$, the gear ratio $a_{\text {trans }}$, the mechanical power losses $P_{\text {loss }}$ resulting from the gear friction (taken into account at higher speed), and other friction losses (of the bearings and the machine) taken into account by means of the efficiency $\eta_{\text {trans }}$.

The torque acting on the axis of the forward running $\left(\omega_{e m}>0\right)$ electrical machine, can be determined according to the following relations:

- in motor mode in the I. quadrant

$$
T_{\text {trans }}=\frac{T_{\text {wheel }}+\frac{P_{\text {loss }}}{\omega_{\text {trans }}}}{a_{\text {trans }} \eta_{\text {trans }}} \text {, if } T_{\text {wheel }}>0 \text {; }
$$

- in regenerative braking mode in the II. quadrant

$$
T_{\text {trans }}=\frac{T_{\text {wheel }}+\frac{P_{\text {loss }}}{\omega_{\text {trans }}}}{a_{\text {trans }}} \eta_{\text {trans }}, \text { if } T_{\text {wheel }}<0 .
$$

The parameters of the gearbox, used for simulation, were $a_{\text {trans }}=3$ is the gear ratio, $P_{\text {loss }}=50 \mathrm{~W}$ is the power loss resulting from gear friction, $\eta_{\text {trans }}=98 \%$ is the efficiency corresponding to other losses.

The next block in the electric vehicle simulation model is the electrical machine, which must exert the $T_{e m}$ axis torque, according to the equation of motion

$$
T_{e m}=T_{\text {trans }}+J_{m} \frac{d \omega_{e m}}{d t},
$$

where $\omega_{e m}=\omega_{\text {trans }}$ is the angular velocity of the motor and $J_{m}$ is the total inertia reduced to the motor axis (including the inertia of the rotor), assumed for the simulation as $0.0025 \mathrm{~kg} \mathrm{~m}^{2}$.
The electrical power $P_{\text {el_req }}$ at the machine terminals is calculated from the axis torque and the rotor angular velocity. In the case of forward driving $\left(\omega_{e m}>0\right)$ it can be determined as follows:

- in motor mode in the I. quadrant

$$
P_{e l_{r e q}}=\omega_{e m} T_{e m} \frac{1}{\eta_{e m}\left(\omega_{e m}, T_{e m}\right)} ;
$$

- in regenerative braking mode in the II. quadrant

$$
P_{\text {el_req }}=\omega_{e m} T_{e m} \eta_{e m}\left(\omega_{e m}, T_{e m}\right) .
$$

where $\eta_{e m}$ is the efficiency corresponding to the electrical and iron losses of the electrical motor.

In the $1^{\text {st }}$ quadrant the electrical machine drives, while in the $2^{\text {nd }}$ quadrant it brakes.

In the simulations from this study, the efficiency $\eta_{e m}=f\left(\omega_{e m}, T_{e m}\right)$ of the motor was considered using the „eta_EM_map” data structure of the „QSS” Simulink ${ }^{\circledR}$ library [6].

The battery and the supercapacitor were simulated using the models available in the „Battery” and the „Supercapacitor” libraries [6].

The inputs of these models are the instantaneous values of the required powers $P_{\text {req_BAT }}$ and $P_{\text {req_sc }}$ (see Figure 1), determined by the energy management algorithm based on the state of charge (SOC) of the battery and the state of energy (SOE) of the supercapacitor, as follows:

$$
\begin{aligned}
& S O C=\frac{Q_{B A T}}{Q_{B A T \_N O M}} ; \\
& S O E=\frac{E_{S C}}{E_{S C_{-} N O M}} ; \\
& P_{\text {el_req }}=P_{\text {req_BAT }}+P_{\text {req_SC }}
\end{aligned}
$$

In $(11, \mathrm{a})$ and $(11, \mathrm{~b}) Q_{B A T}$ is the charge quantity stored in the battery, and $E_{S C}$ is the instantaneous value of the energy stored in the supercapacitor.

The supercapacitor power $P_{\text {req_sc }}$ used in $(11, \mathrm{c})$, is determined by the energy management algorithm, based on the fuzzy inference rules and taking into account the electric power $P_{\text {el_req }}$ required to drive the vehicle, resulting from the vehicle model.

The simulations presented in this paper used $80 \%$ initial battery charge from the nominal $\left(Q_{B A T_{-} N O M}=100 \mathrm{Ah}\right)$, and $90 \%$ initial energy of the $\bar{C}_{S C}=48 \mathrm{~F}$ supercapacitor $\left(E_{S C_{-} N O M}=1215 \mathrm{~kJ}\right.$, $\left.U_{S C \_N O M}=225 \mathrm{~V}\right)$.

The fuzzy rule-based energy management algorithm of the HESS was simulated in Matlab-Sim- 
ulink® environment using the „Fuzzy Logic Controller" model, which has per unit inputs and outputs. Thus, at the input, the $P_{\text {el_req }}$ power was normalized to $P_{N}=16 \mathrm{~kW}$ while the output results were multiplied by this base, because the „Battery” and „Supercapacitor” blocks require inputs in kilowatts.

The diagrams a) and b) in Figure 3 show the speed and acceleration, respectively, generated by the NEDC driving profile, while diagram c) shows the power sharing between the battery and the supercapacitor, as it results from the energy management algorithm.

In the diagram c) of Figure 3 it can be observed that during the 20-minute driving cycle, almost half of the instantaneous electric power required from the HESS is provided by the supercapacitor. The power required from the battery $\left(P_{\text {req } B A T}\right)$ is determined according to the relations $(10, \mathrm{~b})$ and $(10, c)$.

During the driving cycle, the supercapacitor voltage decreased from the initial $90 \%$ to about $45 \%$.

In the diagram a) of Figure 4 the states fed back to the energy management algorithm are represented. SOC is the state of charge of the battery, and SOE is the state of energy of the supercapacitor, both functions of the NEDC driving profile.

The diagram b) of Figure 4 shows the total electric power requirement $P_{\text {el_req }}$ input of the fuzzy

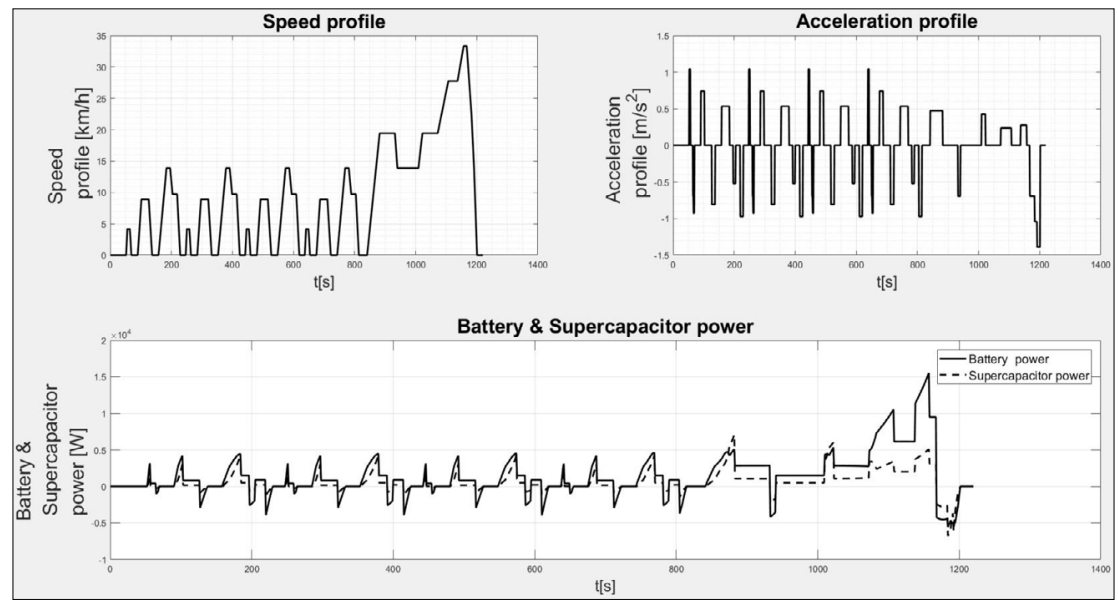

Figure 3. Simulation results illustrating the power sharing process: a) the vehicle speed according to the $N E D C$ driving profile; $b$ ) the vehicle acceleration according to the NEDC driving profile; $c$ ) the power de-mand shared between the battery (continuous line) and the supercapacitor (dashed line).

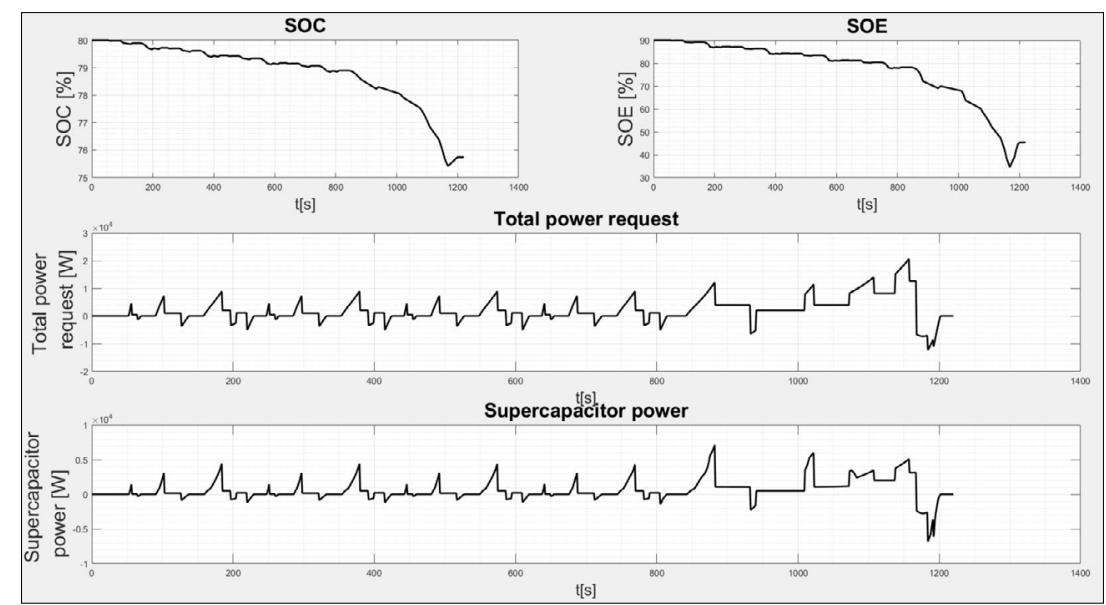

Figure 4. Simulation results using the fuzzy rule-based EMA: a) the battery state of charge SOC; $b$ ) the supercapacitor state of energy SOE; c) the total required electric power $P_{\text {el_req; }}$;) the power required from the supercapacitor $P_{\text {req_sc }}$. 
rule-based EMA, computed by the „Electrical machine” block of the simulation model according to $(10, c)$.

The diagram c) of Figure 4 shows the per unit value of the supercapacitor power $P_{\text {req_sc }}$ determined by the fuzzy rule-based EMA, which avoids excessive battery power stress.

Tuning of the EMA was performed by variation of the input and output membership function parameters and by variation of the inference rules. In cases when the state of energy of the supercapacitor drops below $10 \%$, the energy management algorithm provides the full power needed to drive the vehicle, from the battery.

\section{The HESS power flow control}

In the literature there can be found several topologies of hybrid energy storage systems. Namely, in case of two energy sources and a single load, a number of seven HESS topologies are mentioned [8].

One HESS version is the active parallel topology shown in Figure 5 In this case, both energy sources are connected to the DC-link by means of bidirectional DC-DC converters [9].

This topology is called active because the voltage, current and power of both energy sources can be controlled by the DC-DC converters.
Using these converters, power sharing can be solved between the Li-ion battery and the supercapacitor, i.e., between the power sources that supply the electrical drive of the vehicle.

Bidirectional DC-DC converters are needed because the HESS delivers energy in driving mode but has to store the recovered energy in regenerative braking mode.

Due to the bidirectional energy flow, in proper moments the vehicle can charge the supercapacitor (in low energy state) from the battery, preparing it to deliver high power peaks if necessary.

\section{The bidirectional DC-DC converter}

The active parallel HESS contains two bidirectional converters, both with the load side connected to the same DC-link, formed by a capacitor tank, which represents the power source for the electrical drive of the vehicle (Figure 5) [8].

As in practice the battery and the supercapacitor of the electric vehicle are not isolated galvanically, the DC-DC converters included in this study are high efficiency bidirectional converters without galvanic isolation [10].

The interleaved four-phase bidirectional DC-DC converter shown in Figure 6 contains two pairs of magnetically coupled chokes [10].

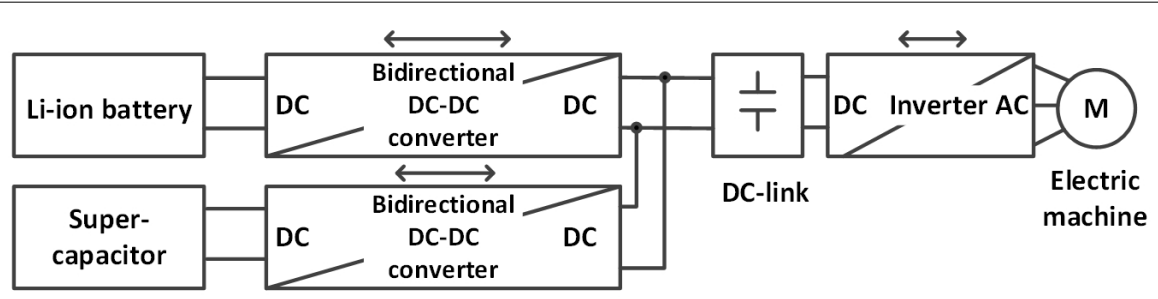

Figure 5. Block diagram of the active parallel hybrid energy storage system (HESS).

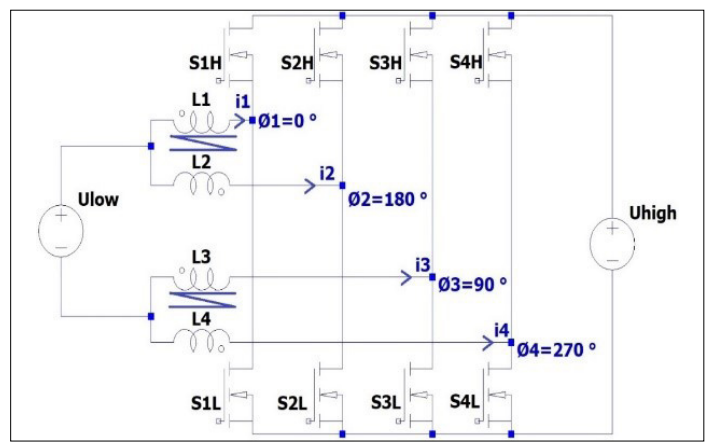

Figure 6. The topology of the interleaved four-phase bidirectional $D C$ - $D C$ converter [10]

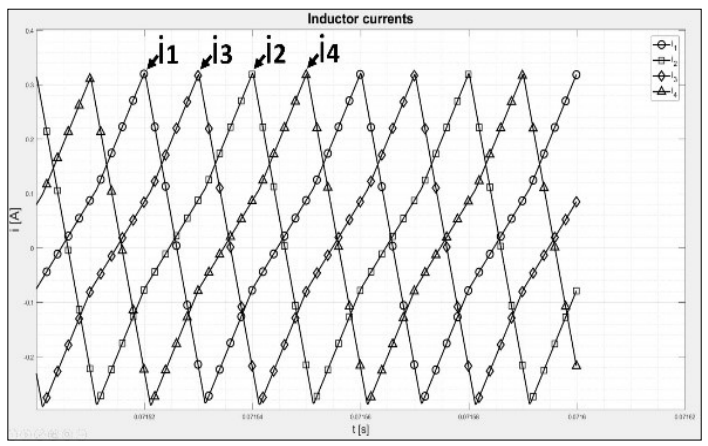

Figure 7. The input currents of the interleaved four-phase bidirectional DC-DC converter on the low voltage side. 
The converter has eight power MOSFET transistors, which form four half-bridges (legs). The highside and low-side transistors from each leg are driven by complementary gate signals $\left(S_{1 H}\right.$ is complementary of $S_{1 L}$, etc.).

The magnetic coupling is a solution applied to increase the converter efficiency and to reduce of the size of the chokes $[11,10]$.

The simulated interleaved currents $\left(i_{1}, i_{2}, i_{3}\right.$, and $i_{4}$ ) of the magnetically coupled chokes are shown in Figure 7.

The electric angles shown near the legs in Figure 6 represent the phase shifts of the control signals in Figure 8 from the control signal $S_{1 L}$ of the first leg's low-side transistor (these correspond to $T_{s} / 4, T_{s} / 2$, and $3 T_{s} / 4$ time delays, where $T_{s}$ is the switching period of the converter) [10].

It is important to note that for the operation of the interleaved four-phase bidirectional converter, the output side (DC-link side) voltage $\left(U_{\text {low }}\right)$ of the converter must be higher than the input side (battery-side or supercapacitor-side) voltage $\left(U_{\text {high }}\right)$.

Modelling and simulation of the converter was performed in MATLAB/Simulink ${ }^{\circledR}$ environment. The inductances $L_{1}, L_{2}, L_{3}, L_{4}$ of the coupled chokes can be determined as [11]:

$$
L_{1}=L_{2}=L_{3}=L_{4}=\frac{U_{\text {low }} * D_{M A X}}{\Delta I_{L} * f_{S}},
$$

where $U_{\text {low }}$ is the input-side low voltage of the bidirectional converter, $D_{M A X}$ is the maximum duty cycle used to drive the converter, $\Delta I_{L}$ is the maximum choke current ripple, and $f_{s}$ is the switching period of the converter.

\section{The power sharing control of the active parallel HESS}

Based on similar HESS solutions from the literature, we propose the control structure shown in Figure $9[12,13,14]$.

In steady-state the total power delivered by the DC-DC converters in Figure 5 has to cover the load power. If the load power exceeds the sum of the converter powers, that results in the decrease of the DC-link voltage.

Thus, the output of the voltage controller from the control structure shown in Figure 9 represents the reference of the total power $P_{\text {el_req }}$ to be delivered to the DC-link by the DC-DC converters.

This total power need signaled by the voltage controller must be satisfied by the battery and the supercapacitor.

The energy management algorithm of the active parallel HESS determines the instantaneous power $P_{\text {req_SC }}$ to be delivered by the supercapacitor to protect the battery. The power references of the two energy sources can be calculated from:

$$
\left\{\begin{array}{c}
x=\frac{P_{\text {req_SC }}}{P_{\text {el_req }}} 100 \\
P_{\text {req_BAT }}=P_{\text {el_req }}-P_{\text {req_SC }}
\end{array},\right.
$$

where $x$ represents the share of $P_{\text {req_SC }}$ in \% from the total required power.

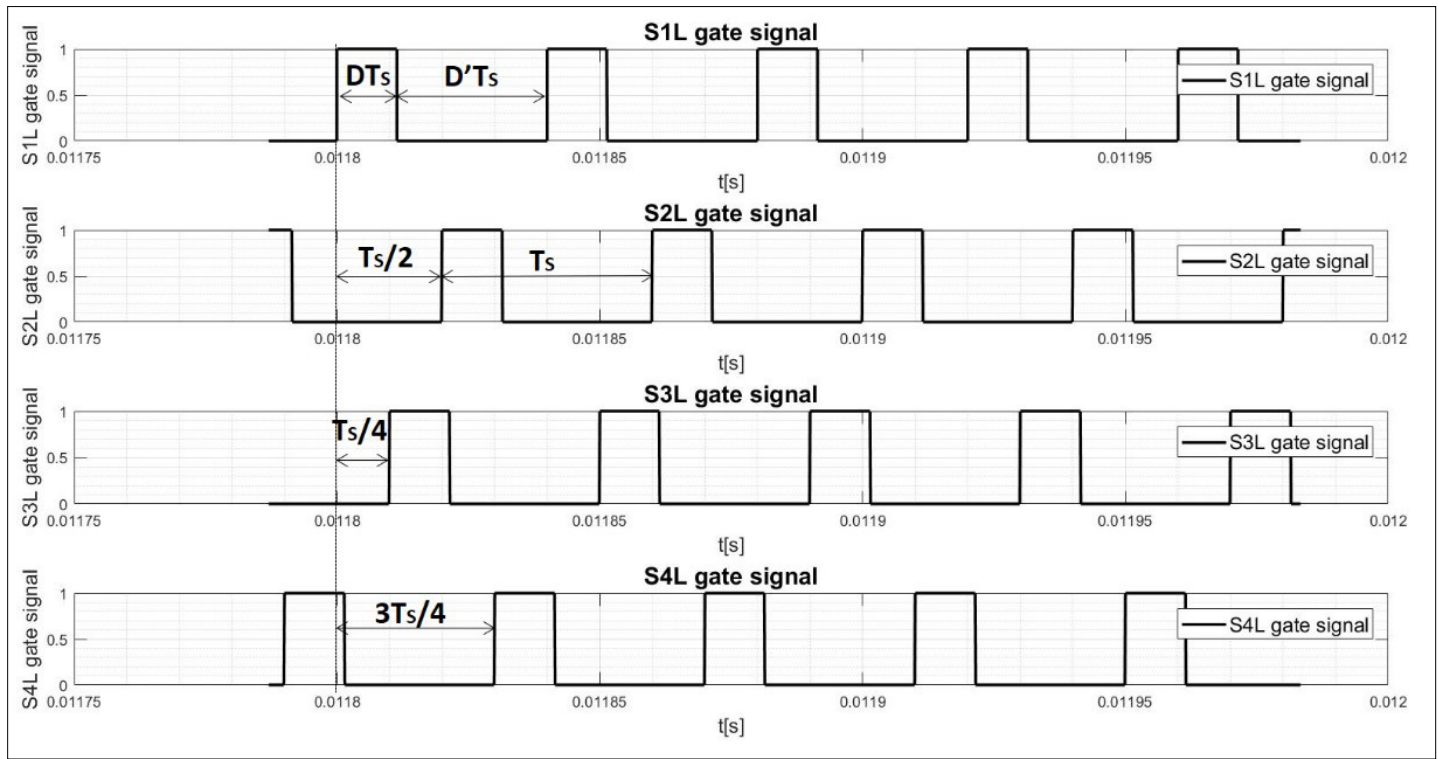

Figure 8. Control signals of the low-side transistors of the four-phase bidirectional DC-DC converter. 


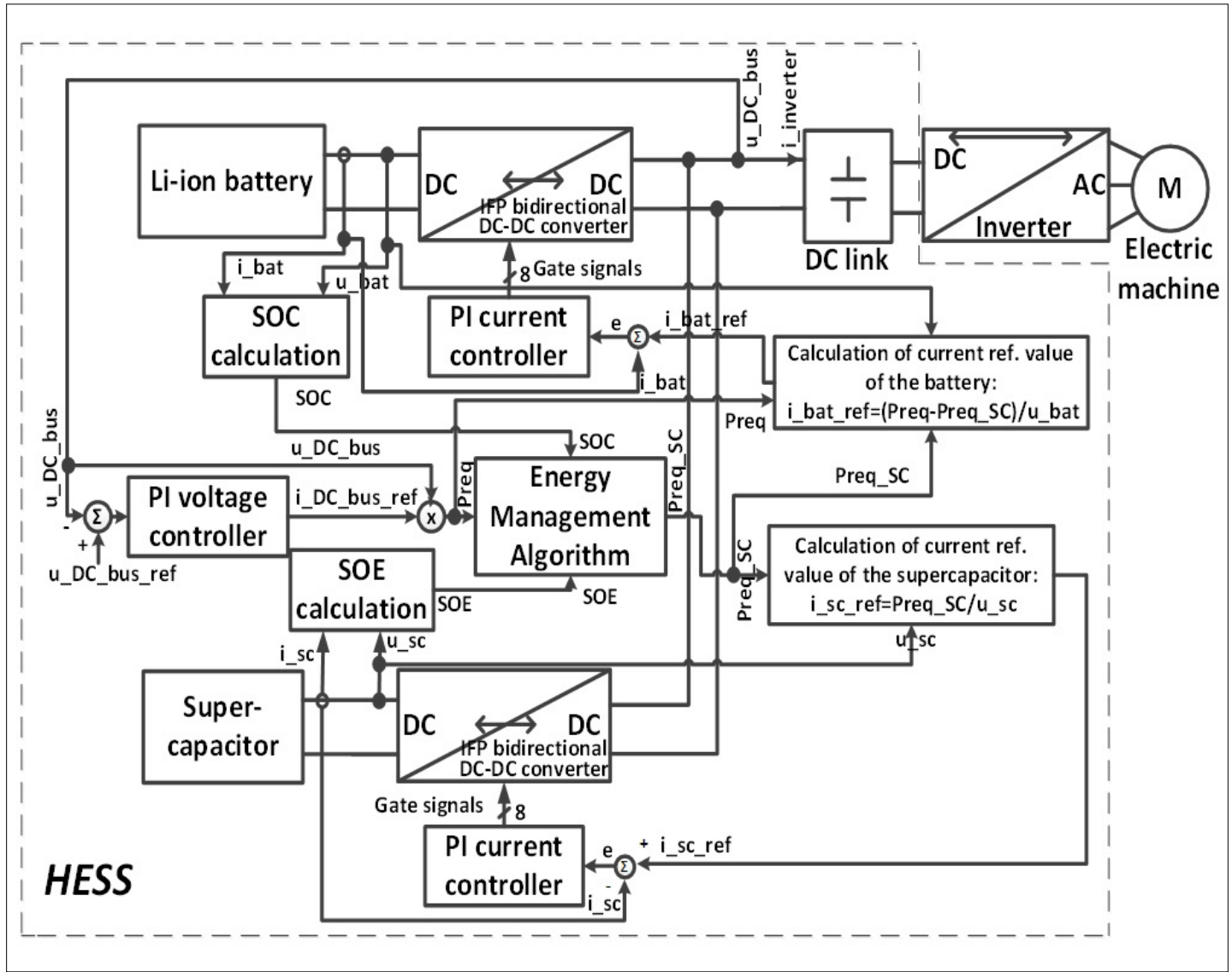

Figure 9. The proposed control structure of the hybrid energy storage system.

In regenerative braking mode $P_{\text {el_req }}$ is negative because the power generated by the machine would increase the DC-link capacitor voltage. This can be prevented only by the storage of the excess energy in the supercapacitor or in the battery.

The current references result from the power shares determined by the energy management algorithm and the voltage levels of the two energy storages:

$$
\left\{\begin{array}{c}
i_{S C_{-} R E F}=\frac{x}{100} \frac{P_{e l_{-} r e q}}{U_{S C}} \\
i_{B A T_{\_} R E F}=\frac{100-x}{100} \frac{P_{e l_{\_} r e q}}{U_{B A T}}
\end{array},\right.
$$

where $U_{S C}$ and $U_{B A T}$ are the supercapacitor and battery voltages, respectively.

\section{Simulation of the active parallel HESS}

Modelling and simulation of the HESS (Figure 5) and of its control structure (Figure 9) was performed in MATLAB/Simulink® environment.
Figure 10 and 11 show the results of the same simulation, in which the electrical drive connected to the DC-link is replaced by an $i_{\text {inverter }}$ current source [diagram a) Figure 10]. Diagram b) in Figure 10 shows the variation of the DC-link voltage (set to $u_{D C \text { bus }}=50 \mathrm{~V}$ by the voltage cotroller) in driving and regenerative braking modes.

Figure 11 shows in the $t \in(20 \mathrm{~ms}-55 \mathrm{~ms})$ time interval the constant-current charging of the $C_{s c}=43$ F supercapacitor, pre-charged to $u_{s c}=32 \mathrm{~V}$ according to the diagram d) of Figure 10. This results in a negative supercapacitor power of about $P_{\text {req_sc }} \approx-150 \mathrm{~W}$ [see diagram c) of Figure 11].

The supercapacitor is charged from the battery via the two DC-DC converters connected to the DClink, according to diagrams b) and c) Figure 11.

In the time interval $t \in(70 \mathrm{~ms}, 96 \mathrm{~ms})$ the HESS operates as an energy supply, and the DC-DC converters cover the power demand of the load, supplying positive DC currents to the DC-link (see diagrams c) and d) in Figure 10. In this case the ratio of the battery and supercapacitor powers is $3 / 7$, 
prescribed by the energy management algorithm [see diagrams b) and c) in Figure 11].

The simulation was performed assuming $u_{b a t}=36 \mathrm{~V}$ and $u_{s c}=20 \mathrm{~V}$.

In the time interval $t \in(96 \mathrm{~ms}, 122 \mathrm{~ms})$ the HESS operates as energy storage, the negative currents of the DC-DC converters meaning that the energy storage system receives - through the inverter - the energy delivered by the load. This is illustrated by diagrams c) and d) in Figure 10 and diagrams b) and c) in Figure 11.

In the time interval $t \in(0 \mathrm{~ms}, 12 \mathrm{~ms})$ the load current is zero and the DC-DC converters must provide energy only for charging the $C_{D C}=200 \mu \mathrm{F}$ apacitor of the DC-link.

In the following the simulation of an electric bicycle is presented, supplied from the above HESS system. The parameters of the bicycle correspond to those of a racing bike [15]. The required maximum power $\left(P_{\text {el_req }}\right)$ has been determined from the forces (2) acting on the vehicle.

The drag force $F_{\text {air }}=10.32 \mathrm{~N}$ was determined using the $\rho=1.18 \mathrm{~kg} / \mathrm{m}^{3}, C_{d}=0,88, A_{\text {front }}=0.362 \mathrm{~m}^{2}$ and $v=7.41 \mathrm{~m} / \mathrm{s}$ parameters.

The parameters used to determine the friction force $\left(F_{\text {friction }}\right)$ were $m=100 \mathrm{~kg}$ the mass of the ve-

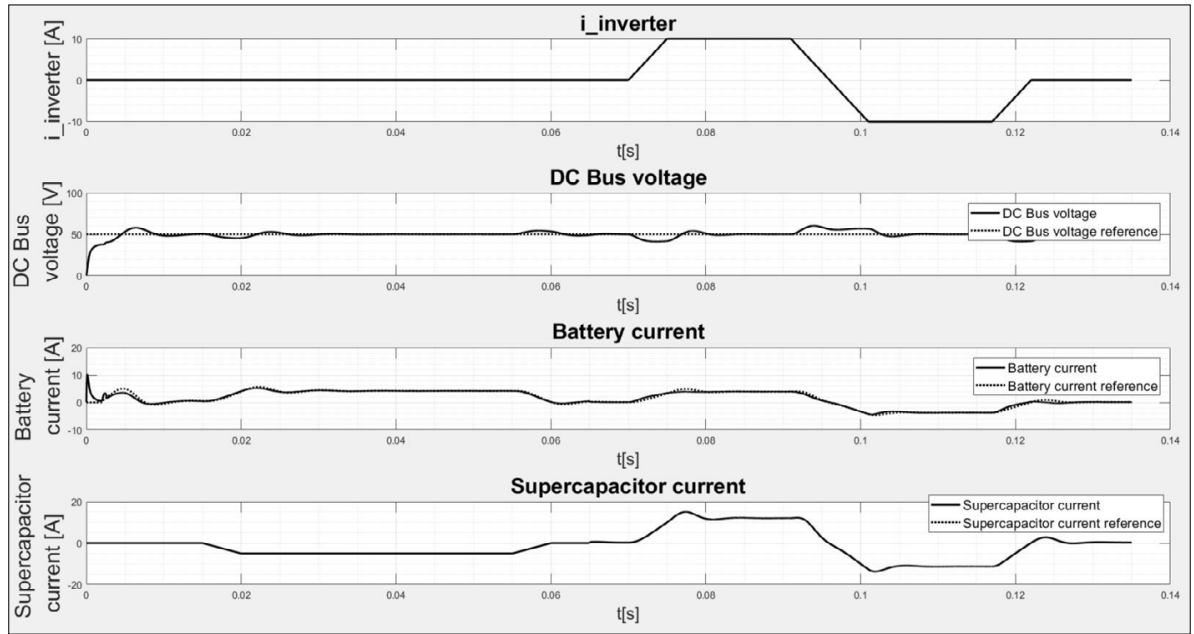

Figure 10. Simulation results: $i_{\text {inverter }}$ the DC-link current delivered by the inverter $(a)$, the $D C$-link voltage $(b)$, the battery current (c) and the supercapacitor current (d).

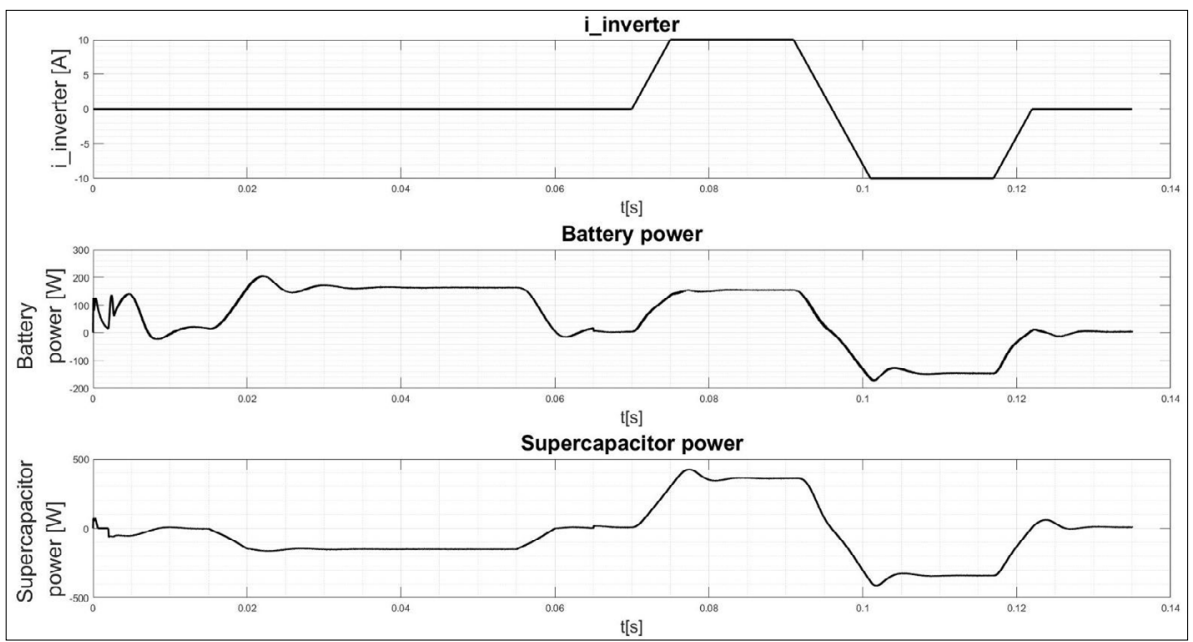

Figure 11. Simulation results that demonstrate two operation modes of the HESS: the evolution of the power sharing between the energy sources in case of the sudden variation of the inverter current (a) at $t=70 \mathrm{~ms}$ and $t=92 \mathrm{~ms}$, and during charging of the supercapacitor from the battery in the time interval $20 \mathrm{~ms}-55 \mathrm{~ms}$. 
hicle (25 $\mathrm{kg}$ the bicycle, and $75 \mathrm{~kg}$ the person riding it), $\mu=0.003, g=9.81 \mathrm{~m} / \mathrm{s}^{2}$ and $\cos \alpha=1$.

The inertial force $F_{\text {inertial }}=25 \mathrm{~N}$ twas determined assuming the acceleration $a_{\text {vehicle }}=0,25 \mathrm{~m} / \mathrm{s}^{2}$.

Considering the radius of the wheel $r_{\text {wheel }}=0.3429 \mathrm{~m}$ the maximum traction force $F_{\text {traction }}=37.97 \mathrm{~N}$ results in a $T_{\text {wheel }}=13 \mathrm{Nm}$ torque.

The diagrams in Figure 12 show the speed (a) and the acceleration (b) representing the driving profile defined in the study. During the $0.25 \mathrm{~m} / \mathrm{s}^{2}$ acceleration, the bicycle reaches $7.41 \mathrm{~m} / \mathrm{s}$ starting from $0 \mathrm{~m} / \mathrm{s}$. During breaking the bicycle speed is reduced to zero with $-0,25 \mathrm{~m} / \mathrm{s}^{2}$ acceleration (deceleration).

The following simulation results demonstrate the power sharing at peak power, in the time periods $t_{2}-t_{1}=43 \mathrm{~ms}$ and $t_{4}-t_{3}=55 \mathrm{~ms}$ from the zones $\mathrm{A}$ and $\mathrm{D}$, for steady-state sharing ratios.

At the beginning of the acceleration period, the initial state of energy of the supercapacitor is $\mathrm{SOE}=95 \%$, and the initial state of charge of the battery is SOC $=95 \%$.

The simulation results in Figure 13 show the evolution in time of the power sharing in the zone A in Figure 12 at the end of the acceleration process and at steady state, required by the energy management algorithm. For acceleration, the HESS must provide $\approx 281 \mathrm{~W}$ peak power. In this time interval, the fuzzy rule-based EMA required $x=88 \%$ power splitting (sharing) ratio.

The power sharing is performed by the control structure shown in Figure 9. The contribution of the supercapacitor to the total required power is $\approx 240 \mathrm{~W}$, while the contribution of the battery is $\approx 34 \mathrm{~W}$, as shown in diagrams a) and b) in Figure 13 .

The simulation results in Figure 14 show the evolution in time of the power sharing defined by the EMA during the braking process of the electric bicycle, at the beginning of the braking process and in steady state, in the zone labelled „D in Figure 12.

At the beginning of the braking process, the initial states were SOE $=50 \%$, and SOC $=95 \%$. During regenerative braking, the HESS was required to store the generated energy at $\approx-89 \mathrm{~W}$ peak power.

The power sharing ratio defined by the fuzzy EMA was $\mathrm{x}=72 \%$, representing $\approx-26 \mathrm{~W}$ and $\approx-64 \mathrm{~W}$ charging powers, as can be observed in diagrams a) and b), Figure 14.
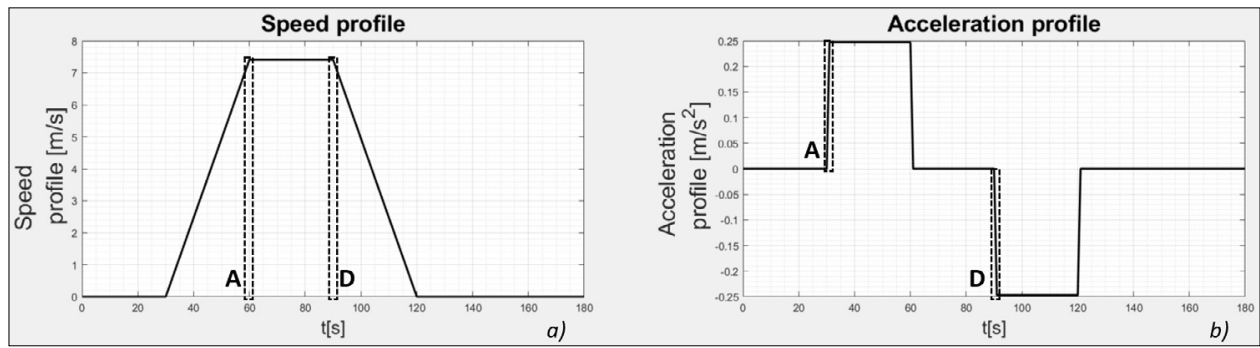

Figure 12. The driving cycle defined for the simulation of the bicycle acceleration and regenerative braking:

a) the speed profile,

b) the acceleration profile.
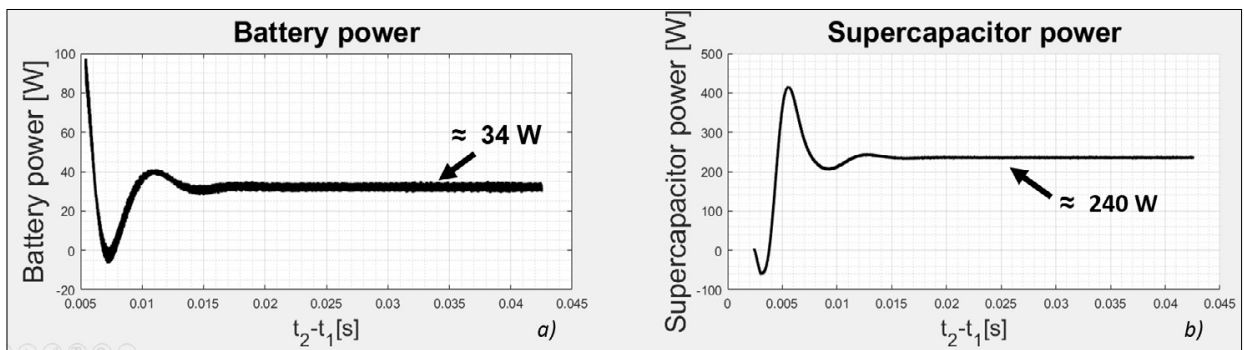

Figure 13. Simulation results at the end of the bicycle acceleration, in the zone A shown in Fig. 12, in the

$t_{2}-t_{1}=43$ ms time period:

a) the variation in time of the power delivered by the battery;

b) the variation in time of the power delivered by the supercapacitor 

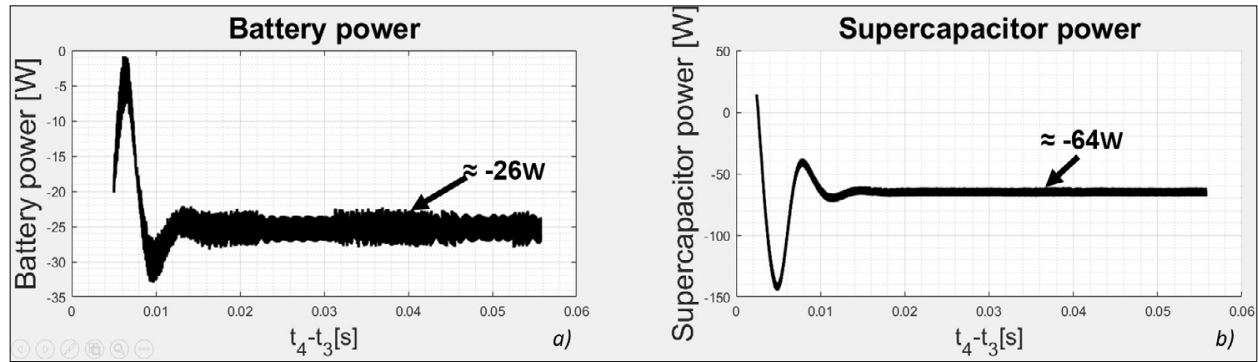

Figure 14. Simulation results in case of the regenerative braking of the bicycle, at the beginning of the braking process, in the zone D shown in Fig. 12, in the time period $t_{4}-t_{3}=55 \mathrm{~ms}$

a) the variation in time of the power delivered by the battery;

b) the variation in time of the power delivered by the supercapacitor.

\section{Conclusions}

The fuzzy rule-based energy management algorithm presented in the paper performs the power sharing in a manner that avoids excessive battery power stresses that can lead to battery damage.

The simulation results support the viability of the control structure of an active parallel HESS based on bidirectional interleaved DC-DC converters.

The parameters of the simulation models correspond to a hybrid energy storage system controlled by the presented fuzzy rule-based energy management algorithm, intended to be implemented in case of a $0.5 \mathrm{~kW}$ electric bicycle.

\section{References}

[1] S. M. Lukic, J. Cao, R. C. Bansal, F. Rodriguez, A. Emadi: Energy Storage Systems For Automotive Applications. IEEE Trans. on Industrial Electronics, 55/6. (2008) 2258-2267.

https://doi.org/10.1109/TIE.2008.918390

[2] Ferencz J., Kelemen A., Imecs M.: Energy management of a hybrid energy storage system. (in Hungarian) In: XXI. International Online Multi-Conference of Energetics and Electrical Engineering \& Computer Science ENELKO \& SzamOkt 2020. EMT, Cluj-Napoca, 2020. 40-45.

https://ojs.emt.ro/index.php/enelko-szamokt/article/view/315/255

[3] H. Yu, F. Cheli, F. Castelli-Dezza, D. Cao, F.-Y. Wang: Multiobjective Optimal Sizing and Energy Management of Hybrid Energy Storage System for Electric Vehicles.

https://www.researchgate.net/publication/322652476_Multi-objective_Optimal_Sizing_and_Energy_Management_of_Hybrid_Energy_Storage_System_for_Electric_Vehicles

[4] Maarten J. van Jaarsveld, Rupert Gouws: An active hybrid energy storage system utilizing a fuzzy logic rule-based control strategy. World Electric Vehicle Journal, 2020/4. 1-24.

https://doi.org/10.3390/wevj11020034
[5] Zhang Q., Deng W., Zhang S., Wu J.: A rule based energy management system of experimental battery/supercapacitor hybrid energy storage system for electric vehicles. Journal of Control Science and Engineering, 2016. 1-17.

https://doi.org/10.1155/2016/6828269

[6] Guzzella L., Amsutz A.: The QSS Toolbox Manual. Swiss Federal Institute of Technology Zurich (ETH Zürich), Measurement and Control Laboratory, June 2005.

[7] Ehsani M., Gao Y., Gay E. S., Emadi A.: Modern Electric, Hybrid Electric, and Fuel Cell Vehicles. 4. Ed., CRC Press, Boca Raton, London, New York, Washington D.C., 2005. 21-34.

[8] J. Cao, A. Emadi: A New Battery/UltraCapacitor Hybrid Energy Storage System for Electric, Hybrid, and Plug-In Hybrid Electric Vehicles. IEEE Transactions on Power Electronics, 27/1. (2012) 122-132.

https://doi.org/10.1109/TPEL.2011.2151206

[9] Ferencz J., Kelemen A., Imecs M.: Control of power electronic converters from an active parallel hybrid energy storage system. (in Hungarian) In: International Online Multi-Conference of Energetics and Electrical Engineering \& Computer Science ENELKO \& SzamOkt 2020. EMT, Cluj-Napoca, 2020. 34-39.

https://ojs.emt.ro/index.php/enelko-szamokt/article/view/316/254

[10] Yu W., Lai J. S.: Ultra high efficiency bidirectional $D C$-DC converter with multi-frequency pulse width modulation. In: Proceedings: APEC 2008 Twenty-third Annual IEEE Applied Power Electronics Conference and Exposition, Austin, Texas, 2008. Piscataway, N.J., IEEE, 1079-1084. https://doi.org/10.1109/APEC.2008.4522856

[11] Kanta S., Plangklang B., Subsingha W.: Design of a Bi-directional DC-DC 4 Phase Interleave Converter for PV Applications. Energy Procedia, 56. (2014) 604-609. https://doi.org/10.1016/j.egypro.2014.07.199

[12] Dulout J., Jammes B., Séguier L., Alonso C.: Control and design of a hybrid energy storage system. 
In: Proceedings of the 2015 17th Conference on Power Electronics and Applications (EPE '15 ECCE-EUROPE 2015), Geneva, Switzerland, 2015. Institute of Electrical and Electronics Engineers (IEEE), 2016. 1-9.

[13] Manandhar U., Ukil A., Kollimalla S. K., Gooi H. B. L.: Application of HESS for PV system with modified control strategy. In: 2015 IEEE Innovative Smart Grid Technologies - Asia (ISGT ASIA), Bangkok, Thailand, IEEE, 2015. 1-6.

https://doi.org/10.1109/ISGT-Asia.2015.7387078
[14] M. B. Camara, H. Gualous, F. Gustin, A. Berthon: Design and New Control of DC/DC Converters to Share Energy Between Supercapacitors and Batteries in Hybrid Vehicles. IEEE Transactions on Vehicular Technology, 57/5.(2008) 1-15. https://doi.org/10.1109/TVT.2008.915491

[15] Wilson D. G.: Bicycling Science. 3. ed. MIT Press, Cambridge, Massachusetts, London, England, 2004. 188-209. 